\title{
In vitro modelling of salinity stress for the selection of stress-tolerant birch lines
}

\author{
$T M$ Tabatskaya $^{1}, O S$ Mashkina $^{1,2, *}$, and $O M$ Korchagin $^{1}$ \\ ${ }^{1}$ All-Russian Research Institute of Forest Genetics, Breeding and Biotechnology, Lomonosova Street, \\ 105, 394087, Voronezh, Russia \\ ${ }^{2}$ Voronezh State University, Universitetskaya Square 1, 394018, Voronezh, Russia
}

\begin{abstract}
This paper examines the salinity stress effect in vitro culture of microshoots of 10 birch clones: Betula pendula L., B. pendula Roth var. carelica (Mercklin) Hämet-Ahti, B. pendula f. 'dalecarlica' (L.f.) Schneid., $B$. pubescens Ehrh. We used economically valuable and genetically diverse (various species, varieties, hybrids, polyploids) birch material from in vitro clone collection. We tested 3 in vitro selection methods on $1 / 2 \mathrm{MS}$ hormone-free nutrient medium: mild - with a prolonged exposure to $0.2 \%$ $\mathrm{NaCl}$; gradual - with a step-by-step increase in osmotic concentration (from $0.2 \%$ to $1 \%$ ); severe - with a sublethal (1\%) NaCl concentration. We established that the gradual method of $\mathrm{NaCl}$ exposure according to the following pattern: $0.2 \% \rightarrow 0 \% \rightarrow 0.5 \% \rightarrow 0 \% \rightarrow 0.75 \% \rightarrow 0 \% \rightarrow 1.0 \%$ resulted in the best selective effect for birch, as it provides a clear differentiation of clones in terms of their salinity tolerance. We identified that the genotype had a significant impact on the preservation of the explants and their ability to regenerate under salinity stress. The study showed that tetraploid clones of downy birch and a triploid clone of Karelian birch of a pronounced mixoploid nature had the greatest salinity tolerance.
\end{abstract}

\section{Introduction}

Abiotic stress (drought, soil salination, soil pollution by heavy metals etc.) has a negative impact on growth, development and productivity of plants (including forest trees) [1-2]. Climate change, for example, has contributed to the increased number of droughts in the European part of Russia in recent years. For instance, a major drought of 2010 with extremely hot weather caused partial (in some cases, mass) die-off of silver birch trees [3]. There are reports of drought deaths in Eucalyptus globulus (Labill.) plantations in Australia [4]. In this regard, plants with improved stress tolerance are becoming more and more popular. As for breeding for resistance to various stress factors, it has become particularly important in recent years. Genetic diversity in plant species is a prerequisite for the perspective of successful breeding for stress resistance. For example, it has been demonstrated [5] that Betula halophila, the birch species endemic to China, has a high salt tolerance, which, according to the authors, is determined genetically and is related to the

\footnotetext{
* Corresponding author: mashkinaos@ mail.ru
} 
large number of differentially expressed genes. Genotypic differences in salinity tolerance have been found in poplar [6-7] and other plants [8-9].

In vitro modelling of abiotic stress is one of the promising avenue for plant breeding for resistance to negative environmental factors. The benefits of in vitro selection include the strict control of the cultivation conditions and nutrient medium composition. The use of in vitro techniques accelerates plant breeding and allows the breeders to save and quickly reproduce the occasional specimens acquired [10-13].

There have been some positive results on selecting of stress-tolerant plants through in vitro selection, but mainly for agricultural and fruit crops [8, 12, 14-19]. The researchers have used seedlings, callus tissues, cell suspension cultures, and isolated organs as explants $[8,11,13-14,17,20-21]$. But only few studies on in vitro selection have addressed forest tree plants so far [7, 22-25], although such studies would be of great value.

Researchers from different countries have outlined the main objectives of in vitro selection: to develop an algorithm for constructing in vitro selective model systems, to obtain plants with increased tolerance to abiotic stresses, to develop the micropropagation technologies for these plants [8, 10, 13, 17, 20, 26-27].

The most common abiotic stress factors are known to be drought and salination. In vitro culture has been used extensively to study the impact of these factors on plants [17, 20, 28]. Increasing concentrations of sodium chloride $(\mathrm{NaCl})$ in the culture medium represents both salinity stress and osmotic stress facilitating the selection of salt-tolerant and droughtresistant forms [12-14, 17]. Moreover, $\mathrm{NaCl}$ salinity is known to produce the greatest negative effect on plants $[1,10]$. An excess of $\mathrm{NaCl}$ interferes with the basic physiological functions, disrupts ion homeostasis, decreases the nutrient absorption in cells, damages cell membranes, and has a toxic effect on numerous biochemical processes in plants, resulting in overall negative effect on plant growth $[1,7,21]$.

Previously, we had developed a biotest system based on Scots pine callus cultures under saline conditions (on NaCl-supplemented nutrient media) and demonstrated its potential for the selection of drought-resistant genotypes [29]. This became the basis for in vitro selection of deciduous woody plants (birch, in particular).

The genus Betula L. includes 120 species and represents one of the highly valuable forest-forming trees of Russia. It's suitable for protective afforestation, which requires salttolerant and drought-resistant forms. In the European part of Russia, the most common species are silver birch (Betula pendula Roth.) and downy birch (Betula pubescens Ehrh.). A special place among various forms of silver birch is occupied by Karelian birch (Betula pendula Roth var. carelica (Mercklin) Hämet-Ahti), because of its decorative patterned wood texture. Unlike other trees, its wood is sold by weight $(\mathrm{kg})$ and not by volume $\left(\mathrm{m}^{3}\right)$ [30]. Another interesting variety of silver birch is dalecarlica birch (Betula pendula $\mathrm{f}$. 'dalecarlica' (L.f.) Schneid.) widely used in landscape gardening due to its beautiful deeply dissected leaves.

Previously, we had created an in vitro clone collection, which represents high genetic diversity (species, varieties, hybrids, polyploids) of birch [31].

The aim of this research was to study the response of different in vitro clones to sodium chloride-induced salt stress and to develop an algorithm for in vitro selection of birch in order to select stable lines.

\section{Materials and methods}

This study was based on microplants of 10 birch clones from our in vitro collection: Betula pendula L. (d1, d5, P1); B. pendula Roth var. carelica (Mercklin) Hämet-Ahti (18k, Ap); B. pendula f. 'dalecarlica' (L.f.) Schneid. (R1, R2); B. pubescens Ehrh. (2psh, 3psh, 6psh). All clones from the collection were maintained in vitro using our method [31] - by rare 
subculturing (once in 5-6 months) of microplants on 1/2 MS hormone-free nutrient medium [32].

We used 1-1.5-cm-long micro-shoot segments with one axillary bud as explants to study the effect of in vitro salinity stress. The composition of the $1 / 2 \mathrm{MS}$ nutrient medium was modified by addition of sodium chloride $(\mathrm{NaCl})$ at concentrations of $0.2-1 \%$, with different duration and sequence order. As a control we used explants cultivated on nutrient medium without $\mathrm{NaCl}$.

We tested 3 in vitro selection methods:

- mild - with a single but prolonged (for 3 months) exposure to $\mathrm{NaCl}$ at $0.2 \%$ concentration;

- $\quad$ gradual - with a step-by-step increase in osmotic concentration (from $0.2 \%$ to $1 \%$ ), alternating selective and non-selective cultivation conditions $(0.2 \% \rightarrow 0 \% \rightarrow 0.5 \% \rightarrow 0 \%$ $\rightarrow 0.75 \% \rightarrow 0 \% \rightarrow 1.0 \%)$

- $\quad$ severe - with a sublethal $(1 \%) \mathrm{NaCl}$ concentration.

In the last two cases, the duration of the cultivation cycle was 50 days (20 days of salt exposure and 30 days of cultivation on medium without $\mathrm{NaCl}$ ).

In each case of in vitro selection method, after salt exposure, birch cultures were propagated and tested under normal conditions (without stress) for their preservation rate, growth and morphological features (to determine whether developmental abnormalities were present).

The cultivation conditions were as follows: temperature of $25 \pm 2^{\circ} \mathrm{C}$, photoperiod consisting of 16 hours of light and 8 hours of darkness, illumination of $2.0 \mathrm{klx}$.

We used glass test tubes $(21 \times 200 \mathrm{~mm})$ with aluminum foil caps as culture tubes, microshoots were placed each in a separate tube on agarized $(6 \%)$ nutrient medium. Each experiment was replicated 3 times, 20 microshoots for clone.

Stress tolerance was assessed based on preservation (viability) of cultures, their growth, and morphological changes.

The statistical analysis of the results was done using the «Stadia» v.7.0 software (http://top-torrent.ws/soft-torrent/4463-camtasia-studio-70.html, «TechSmith Corporation», USA). The pooling and processing of data procedure is given in Kulaichev's work [33]. We used the Student's $t$-test to compare the samples. Effect of the «belonging to a certain clone» factor was determined by non-parametric one-factor Kruskal-Wallis analysis of variance. Cluster analysis was performed using normalized Euclidean distances and complete linkage classification method.

\section{Results and discussion}

Analysis of experiments performed beforehand demonstrated that under the light mode ( $\mathrm{NaCl} 0.2 \%$ ) of short-term (20 days) salinity stress birch plants showed sharp interclonal differences (initially 10 clones were tested) on the basis of preservation of the explants (microshoots) - from 10 to $90 \%$ compared to $80-100 \%$ in the control. This confirmed that birch is very sensitive to salinity under in vitro conditions and allowed us to differentiate the clones primary into 1) stable (3psh, 6psh, Ap; $18 \mathrm{k}, 2 \mathrm{psh}, \mathrm{R} 2$ ) with a preservation rate varying from 40 to $90 \%$ and 2) sensitive (d.1, d.5, Pv1, R1) with a preservation rate varying from 10 to $30 \%$ (Fig. 1). Stable clones were characterized by a higher regenerative potential $-50-80 \%$ of explants showed signs of shoot formation, there were $60-90 \%$ of rooted microplants. For the other group, these figures did not exceed $40 \%$ and $40-50 \%$, respectively. It should be noted that when the general regenerative activity indicators (such as growth, shoot formation, rooting ability of microshoots) declined, the most notable interclonal differences were based on plants' preservation rate. 


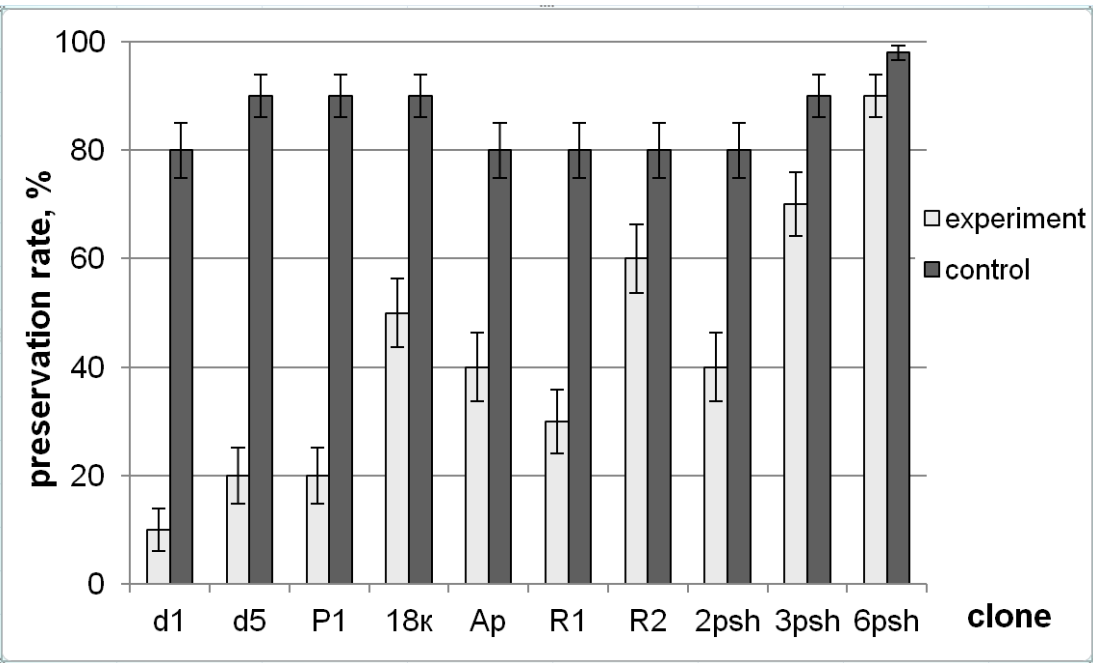

Fig. 1. The preservation of microshoots of birch clones under the experimental conditions (1/2 MS + $\mathrm{NaCl} 0.2 \%, 20$ days) and the control conditions (1/2 MS, 20 days).

The graph shows arithmetic means and confidence intervals for clones of silver birch (d1, d5, P1), Karelian birch (18k, Ap), dalecarcia form of silver birch (R1, R2), downy birch (2psh, 3psh, 6psh).

The selection process effectiveness is determined not only by the preservation rate after stress, but also by the preservation of plants' regenerative potentials. Therefore, in later experiments, we referred to preservation of experimental samples as the percentage of cultures that survived salinity stress and were able to resume normal growth and development afterwards (i.e., that preserved their regenerative potential), as this figure reflects both morphological and physiological state of the explants.

At the further stages of the study, we tested three in vitro selection methods using 6 preselected (the most salt-tolerant) birch clones. The results of comparative analysis of preservation of samples depending upon the selection scheme are presented in table 1.

Table 1. Birch microshoot preservation rate (\%) depending upon in vitro selection mode.

\begin{tabular}{|c|c|c|c|c|}
\hline \multirow{2}{*}{ Clone } & \multirow{2}{*}{ Control } & \multicolumn{3}{|c|}{ Mode of exposure to NaCl } \\
\cline { 3 - 5 } & & mild & gradual & severe \\
\hline $2 \mathrm{psh}$ & $80.0 \pm 1.4$ & $20.1 \pm 0.6$ & $17.8 \pm 0.1$ & $6.6 \pm 0.1$ \\
\hline $3 \mathrm{psh}$ & $90.3 \pm 1.4$ & $45.3 \pm 0.3$ & $60.0 \pm 0.3$ & $13.4 \pm 0.3$ \\
\hline $6 \mathrm{psh}$ & $90.0 \pm 0.3$ & $43.1 \pm 0.5$ & $62.2 \pm 0.1$ & $18.4 \pm 0.1$ \\
\hline $18 \mathrm{k}$ & $90.3 \pm 1.4$ & $16.1 \pm 0.3$ & $22.8 \pm 0.6$ & 0.0 \\
\hline $\mathrm{Ap}$ & $81.7 \pm 2.2$ & $9.1 \pm 0.2$ & $10.0 \pm 0.3$ & 0.0 \\
\hline R2 & $85.0 \pm 1.4$ & $20.8 \pm 0.2$ & $13.4 \pm 0.3$ & $10.1 \pm 0.3$ \\
\hline Mean value & $86.2 \pm 0.8$ & $25.8 \pm 1.9^{*}$ & $31.1 \pm 2.9^{\mathrm{a}}$ & $8.1 \pm 1.0^{*}$ \\
\hline \multicolumn{2}{|c}{${ }^{\mathrm{a}}$ differences between experimental samples and the control are significant at $\mathrm{p}<0.001}$. \\
\hline
\end{tabular}

Most researchers in similar experiments with plants start with the sublethal concentration of a selective agent, as a result a significant part of the experimental samples die $[8,20,27,34]$. In our experiments the severe mode of in vitro selection $(\mathrm{NaCl}, 1.0 \%)$ resulted in the maximum degree of damage to birch microshoots, which is consistent with the results obtained for other plants. On average, the preservation rate was 10 times lower compared to the control $(8.1 \%$ with variation from 0 to $18.4 \%$ depending on the clone, 
compared to $86.2 \%$ in the control). The occasional preserved samples of downy birch were characterized by poor growth, apical or whole-plant necrosis, had smaller leaves with pronounced chlorosis, closer internodal spacing, short thickened roots (Fig. 2). We also observed loss of apical dominance, manifested in auxiliary shoot formation (Fig. 2B).

Table 1 shows that in cases of mild and gradual mode of exposure to $\mathrm{NaCl}$ along with a general negative impact of the stress factor (inhibition of growth, loss of viability), there is also a noticeable clone-specific variation in the birch plants' preservation (depending on the genotype). This allowed us to re-differentiate the clones in terms of their salinity tolerance.

In case of the mild mode $(\mathrm{NaCl}, 0.2 \%$, for 3 months), the preservation rate reached an average of $25.8 \%$ which was 3 times lower compared to the control. We noted genotypic differences in the plants' response to induced salinity stress. Thus, Ap clone of Karelian birch had the lowest preservation rate (9.1\%), two clones of downy birch $-3 \mathrm{psh}$ and $6 \mathrm{psh}-$ the highest preservation rate (45.3 and $43.1 \%$, respectively), while for the third clone of downy birch it was 2 times lower (20.1\%), which is also lower than the average figures for this method of selective exposure to $\mathrm{NaCl}$. At the same time, in the control the microshoots' preservation rate of the same clones was equally high (80-90\%), Table 1.

After the removal of salt stress the plants did not fully resume their regenerative processes. Inhibition of growth, loss of apical dominance, apical or whole-plant necrosis was observed in most explants. The exceptions were the experimental samples of a R2 clone of the dalecarlica birch, which formed fully functional microplants.

The gradual method of selection (with the salt stress increasing step by step) resulted in the continuation of the trend revealed with the other two selection methods: the collection clones tended to differentiate in terms of their salinity tolerance. Thus, the Karelian birch clone (Ap) had the lowest number of preserved plants $(10.0 \%)$ while for $3 p s h$ and $6 \mathrm{psh}$ clones it was the highest ( 60 and $62 \%$, respectively). For the 2 psh clone of the downy birch, the preservation rate did not exceed $17.8 \%$. Plants highly resistant to salinity stress, selected by the gradual method, showed a complete recovery of growth and formed fully functional plants under normal cultivation conditions (without stress), fig. 3.

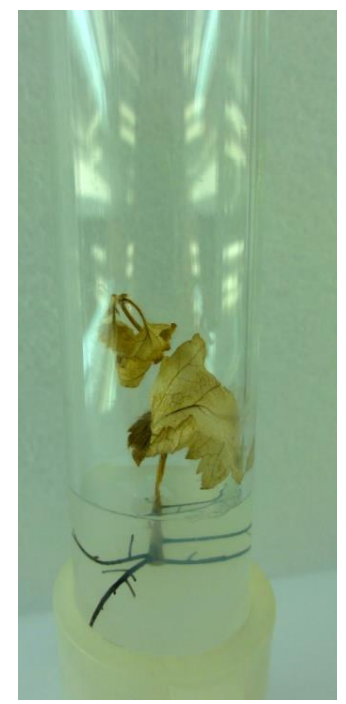

(a)

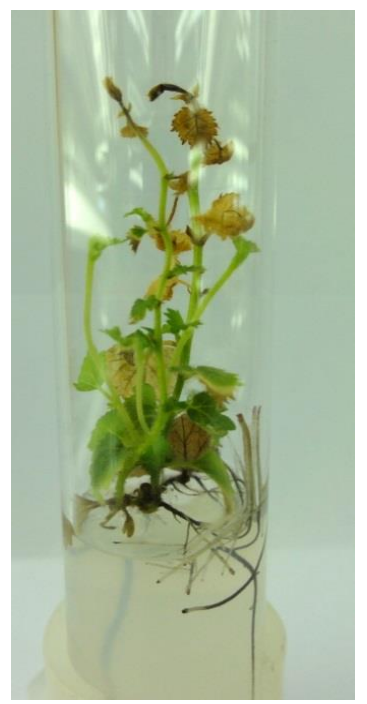

(b)

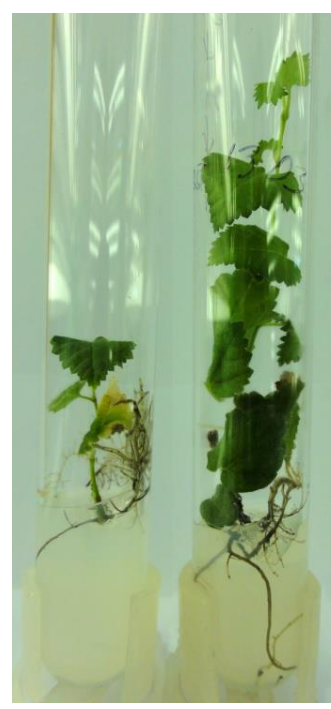

(c) (d)

Fig. 2. Morophogenesis of birch explants (2psh clone) after the severe mode of in vitro selection $(1 / 2$ $\mathrm{MS}+\mathrm{NaCl}, 1.0 \%)$ : A - whole-plant necrosis; $\mathrm{B}$ - apical necrosis; C - inhibition of growth; $\mathrm{D}$ control (microplant that was not subjected to salt stress). 


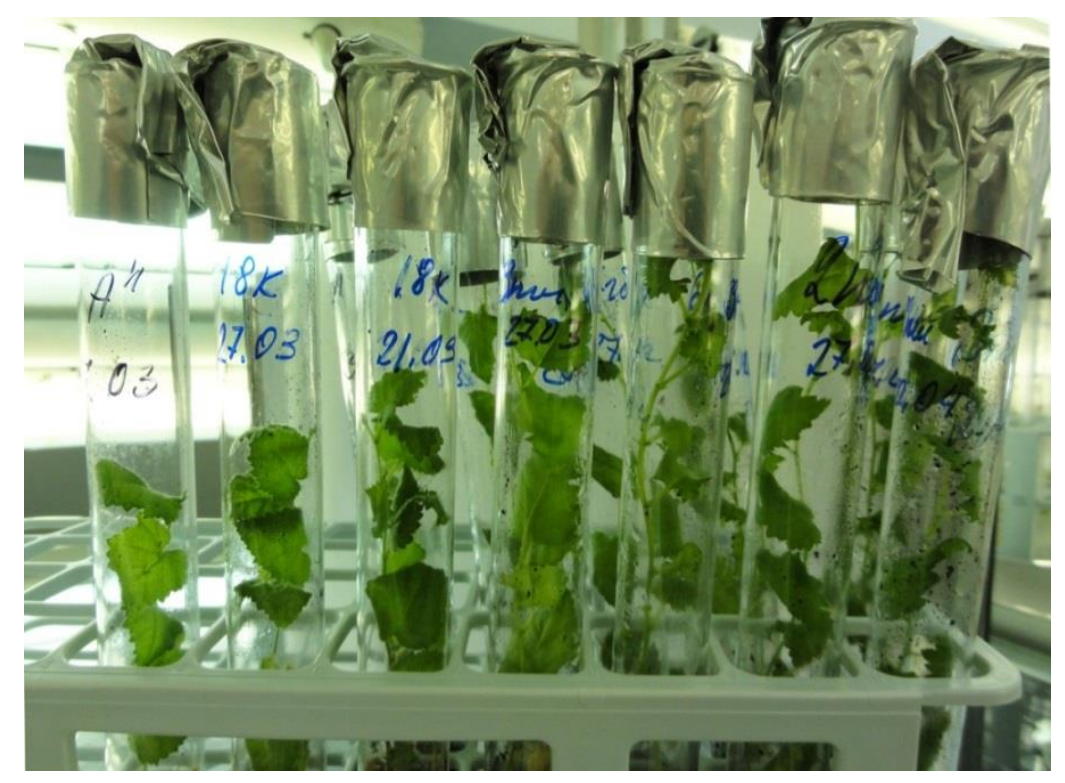

Fig. 3. General view of birch microplants under normal cultivation conditions (without stress), selected by the gradual method of in vitro selection.

Thus, a comparative analysis of the results of severe and gradual selection methods with an equal final concentration of sodium chloride $(1.0 \%)$ showed that the first method led to a significantly lower preservation of plants and their capacity to regenerate than the second one. For example, the average plants' preservation, in this case, was 4 times lower $(8 \%)$ compared to the gradual selection methods $(31.6 \%)$. Also, in the latter case, the capacity of samples to regenerate was better preserved, which is important for their reproduction, further study and formation of stable lines. Therefore, we can claim that the gradual method of in vitro selection (with a step-by-step increase in $\mathrm{NaCl}$ concentration according to an experimentally validated scheme: $0.2 \% \rightarrow 0 \% \rightarrow 0.5 \% \rightarrow 0 \% \rightarrow 0.75 \% \rightarrow 0 \% \rightarrow 1.0 \%$ ) is the most favorable for the studied birch clones. The cultivation cycle is 50 days (20 days of salt exposure, then 30 days of cultivation on medium without $\mathrm{NaCl}$ ).

Nevertheless, in all the tested selection methods (i.e., regardless of the concentration, duration and sequence order of salt exposure), the collection clones tend to differentiate in terms of the salinity tolerance.

Dispersion analysis showed that genotypic characteristics of collection clones significantly impact the survival rate and regenerative potencies of experimental samples $(\mathrm{P}<0.001)$. Using cluster analysis, we divided the clones into three groups based on their reaction to salinity stress (Fig. 4): «resistant» (tolerant) - 6psh and 3psh; «medium saltresistant» - 18k and 2psh; «highly sensitive to salinity» - R2 and Ap. 


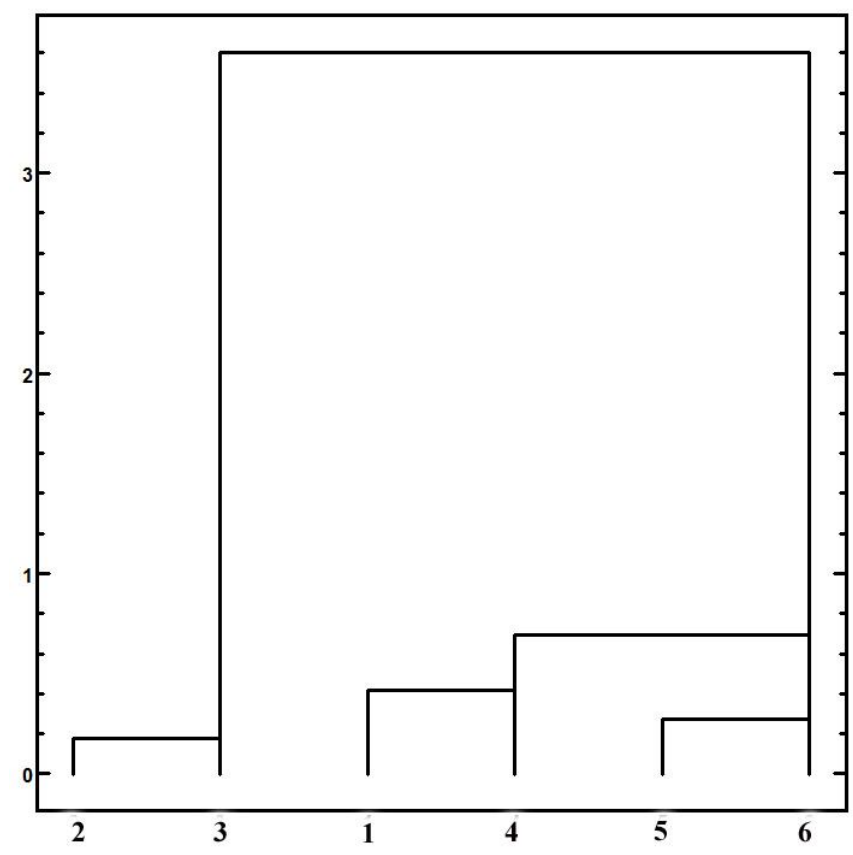

Fig. 4. Dendrogram of cluster distances between birch clones based on the preservation of microshoots in the gradual method of in vitro selection: $1-2 \mathrm{psh}, 2-3 \mathrm{psh}, 3-$ $6 \mathrm{psh}, 4-18 \mathrm{k}, 5-\mathrm{Ap}, 6-\mathrm{R} 2$. The y-axis of the graph represents the cluster distance, the $\mathrm{x}$-axis of the graph - the clone number.

From this perspective, therefore, the highest resistance to salinity was shown by two clones of downy birch - 6psh and $3 p s h$, which could be due to their polyploid nature. Previously, we found that all three clones $(6 \mathrm{psh}, 3 \mathrm{psh}$, and $2 \mathrm{psh})$ are tetraploid $(2 \mathrm{n}=56)$ (Figure 5), which is typical of downy birch, whereas clones of silver birch (d1, d5, P1) and dalecarlica birch $(\mathrm{R} 1, \mathrm{R} 2)$ are diploid $(2 \mathrm{n}=28)$, [31]. However, tetraploid clones, belonging to the same species (6psh, $3 \mathrm{psh}$, and $2 \mathrm{psh}$ ), showed different degrees of stability under similar salinity conditions, which is probably due not only to their ploidy level status, but also to their genotypic characteristics. The microsatellite analysis conducted earlier showed that each of the studied birch clones had a unique genotype [35].

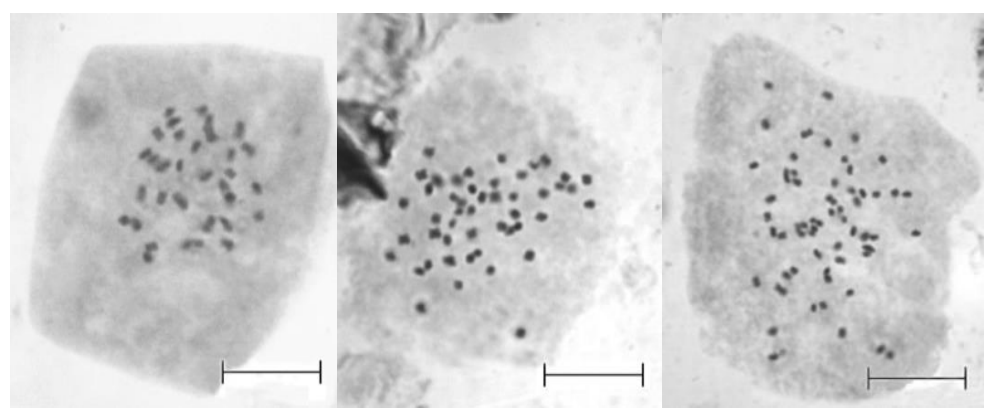

Fig. 5. Metaphase plates with the modal number of chromosomes of root meristem cells of birch microplantcs: A) diploid $(2 \mathrm{n}=28)$ - silver birch (P1 clone); B) triploid $(2 \mathrm{n}=42)-$ Karelian birch (18k clone); C) tetraploid $(2 \mathrm{n}=56)-$ downy birch (3psh clone) $[31]$. Bar $=10 \mu \mathrm{m}$. 
The genetic heterogeneity (natural or induced) of the original plant is known to be the basis of successful breeding and selection of stable genotypes [12, 36]. In addition, in vitro cultivation itself (including the long-term one) can cause genetic changes (somaclonal variation) of cells and tissues [37].

In our experiment, a stable salinity-resistant regenerative line was selected from a longcultivated (for 26 years) triploid clone of 18k Karelian birch (Fig. 5) with a pronounced mixoploid nature $[31,38]$. The percent of cells with a modal triploid set of chromosomes $(2 n=42)$ was on average $61.8 \%$ (with variations for individual ramets from 51.6 to $83.8 \%$ ), diploid $-26.5 \%$, and aneuploid $-11.7 \%$ [31]. The level of myxploidy (the percent of cells in witch number of chromosomes deviated from the modal triploid, $2 \mathrm{n}=42$ ) was on average $34 \%$ (with a variations for individual ramets from 16 to 48\%). Apparently, it was this pronounced genetic heterogeneity of the cell population of clone (triploid-diploid somatic tissue mixoploidy) which allowed us to isolate the stable regenerative line with the help of selective conditions. Therefore, mixoploidy (the presence of cells with different levels of ploidy in the tissue of one organism) can be considered as a source material for in vitro cell and tissue selection.

To avoid the issue of epigenetic adaptation in vitro selection, we re-cultivated the selected regenerative lines (downy birch $-3 \mathrm{psh}, 6 \mathrm{psh}$, and Karelian birch $-18 \mathrm{k}$ ) on a medium with a sublethal $\mathrm{NaCl}$ concentration (1\%). The ability of microplants to resume normal growth and development under normal in vitro cultivation conditions confirms the correctness of the study's results. In the future, we plan to study and test the selected regenerative lines of birch in the field (ex vitro).

Thus, in vitro selection offers great opportunities for increasing the stress tolerance of birch and creating a promising source material for adaptive selection.

\section{References}

1. Chen S, Hawighorst P, Sun J and Polle A 2014 Salt tolerance in Populus: Significance of stress signaling networks, mycorrhization, and soil amendments for cellular and whole-plant nutrition Environmental and Experimental Botany 107 113-124

2. Nowicka B, Ciura J, Szymańska R and Kruk J 2018 Improving Photosynthesis, Plant Productivity and Abiotic Stress Tolerance - Current Trends and Future Perspectives $J$. Plant Physiol. 231 415-433

3. Gazizullin A Kh and Singatullin I K 2014 Birch wood state of upland Volga of the republic of Tatarstan after drough of 2010 year Vestnik of Kazan State Agrarian University 2 99-103

4. Harper R J, Smettem K, Carter J O and Mcgrath J 2009 Drought deaths in Eucalyptus globulus (Labill.) plantations in relation to soils, geomorphology and climate Plant Soil 324 199-207

5. Shao F, Zhang L, Wilson W and Qiu D 2018 Transcriptomic Analysis of Betula halophila in Response to Salt Stress Int. J. Mol. Sci. 193412

6. Chen S and Polle A 2010 Salinity tolerance of Populus Plant Biol. 12 317-333

7. Khudolieieva L and Kutsokon N 2018 In vitro evaluation of salt tolerance of poplars and willows ScienceRise: Biological Science 2 35-38

8. Yegorova N A 2011 The development of methodological basic of lavender cell selection in vitro for $\mathrm{NaCl}$ tolerance Optimization and Protection of Ecosystems 5 173179

9. Benderradji L, Brini F, Kellou K, Ykhlef N, Djekoun A, Masmoudi K and Bouzerzour H 2012 Callus induction, proliferation, and plantlets regeneration of two bread wheat 
(Triticum aestivum L.) genotypes under saline and heat stress conditions Int. Schol. Res. Not. Agr. Vol 2012 p 8

10. Munns R and Tester M 2008 Mechanisms of Salinity Tolerance Annual Review of Plant Biology 59 651-681

11. Sakhanokho H F and Kelley R Y Influence of salicylic acid on in vitro propagation and salt tolerance in Hibiscus acetosella and Hibiscus moscheutos (cv 'Luna Red') Afr. J. Biotechnol. 8 1474-81

12. Rai M K, Kalia R K, Singh R, Gangola M P and Dhawan A K 2011 Developing stress tolerant plants through in vitro selection - An overview of the recent progress Environmental and Experimental Botany 71 89-98

13. Ignatova S A 2011 Cell technology in crop production, genetics and breeding of cultivated plants: problems, opportunities, development of in vitro systems (Odessa: Astroprint) p 224

14. Dasgupta M, Sahoo M R, Kole P C and Mukherjee Ae A 2008 Evaluation of orangefleshed sweet potato (Ipomoea batatas L.) genotypes for salt tolerance through shoot apex culture under in vitro $\mathrm{NaCl}$ mediated salinity stress conditions Plant Cell, Tissue and Organ Cult. 94 161-170

15. Cori P D, Lucioli S, Frattarelli A, Nota P and Forni C 2013 Characterization of the response of in vitro cultured Myrtus communis L. plants to high concentrations of $\mathrm{NaCl}$ Plant Physiology and Biochemistry 73 420-426

16. Shupletsova O N and Shchennikova I N 2016 Results of using cell technologies for creation of new barley varieties resistant against aluminum toxicity and drought Vavilov Journal of Genetics and Breeding 20 623-628

17. Kruglova N N, Seldimirova O A and Zinatullina A E 2018 Callus in vitro as a Model System for Investigation of Plant Stress-Resistance to Abiotic Factors (by the Example of Cereals) Advances in Modern Biology (Uspehi sovremennoj biologii) 138 283-293

18. Elmaghrabi A M, Rogers H J, Francis D and Ochatt S 2018 Toward Unravelling the Genetic Determinism of the Acquisition of Salt and Osmotic Stress Functional Genomics in Medicago truncatul : Methods in Molecular Biology 1822 291-314

19. Jan N, Qazi H A, Ramzan S and John R 2018 Developing Stress-Tolerant Plants Through In Vitro Tissue Culture: Family Brassicaceae Biotechnologies of Crop Improvement $1327-372$

20. Terletskaya L V 2012 Nonspecific reactions of cereals to abiotic stresses in vivo and in vitro (Almaty: Institute of Plant Biology and Biotechnology) p 208

21. Zhang M, Fang Y, Ji Y, Jiang Z and Wang L 2013 Effects of salt stress on ion content, antioxidant enzymes and protein profile in different tissues of Broussonetia papyrifera South African Journal of Botany 85 1-95

22. Kuznetsova T Yu, Titov A F and Vetchinnikova L V 2008 Influence of Cadmium on Morpho-physiological Characteristics of Birch in vitro Lesnoy Zhurnal (Russian Forestry Journal) 3 40-43

23. Fernández R, Bertrand A, Casares A, García R and Tamés R S 2008 Cadmium accumulation and its effect on the in vitro growth of woody fleabane and mycorrhized white birch Environmental Pollution 152 522-529

24. Reshetnikov V N, Spiridovich E V and Nosov A M 2014 Plant biotechnology and perspectives of its development Plant Physiology and Genetics (Fiziologija rastenij $i$ genetika) 46 3-18

25. Vuksanovic V, Kovacevic B, Kebert M, Katanic M, Pavlovic L, Kesic L and Orlovic S 
2019 Clone Specificity of White Poplar (Populus alba L.) Acidity Tolerance in Vitro Fresenius Environmental Bulletin 11 8307-13

26. Bojarczuk K 2004 Effect of Toxic Metals on the Development of Poplar (Populus tremula L. x P. alba L.) Cultured in vitro Pol. J. Environ. Stud. 13 115-120

27. Savita, Virk G S and Nagpal A 2011 In vitro selection of calli of Citrus jambhiri Lush. for tolerance to culture filtrate of Phytophthora parasiticaand their regeneration Phisiol Mol Biol Plants 17 41-47

28. Nezhadahmadi A, Hossain P Z and Faruq G 2013 Drought tolerance in wheat Sci. World J. ID610721(2013)012

29. Amineva E Yu, Tabatskaya T M, Mashkina O S and Popov V N 2017 Assessment of drought resistance of individual genotypes of Pinus sylvestris L. on the basis of in vitro tissue culture method in simulated stress conditions Proceedings of the Saint Petersburg Forestry Research Institute 1 14-22

30. Vetchinnikova L, Titov A and Kuznetsova T 2013 Curly birch: biological characteristics, recourse dynamics, and reproduction (Petrozavodsk: Karelian Research Centre. Russian Academy of Sciences) p 312

31. Tabatskaya T M and Mashkina O S 2020 An experiment of a long-term preservation of a valuable birch genotypes collection using non-hormone nutrient media Lesovedenie 2 147-161

32. Murashige T and Skoog F 1962 A revised medium for rapid growth and bio assays with Tobacco tissue cultures Phisiol. Plant. 15 473-497

33. Kulaichev A P 2006 Methods and tools for complex data analysis (Moscow: Forum: INFRA M) p 512

34. Amineva E Yu, Gureev A P, Tabatskaya T M, Mashkina O S and Popov V N 2019 Genotypic variability of Pinus sylvestris L. on the drought-resistance attribute Vavilov Journal of Genetics and Breeding 23 15-23

35. Grodetskaya T A, Rzhevsky S G, Fedulova T P, Tabatskaya T M and Mashkina O S 2018 Identification of Betula pendula Roth var. carelica and Betula pubescens Ehrh. genotypes with the use of microsatellite markers Proceedings of Voronezh State University. Series: Chemistry. Biology. Pharmacy 3 121-128

36. Mohamed M A H, Harris P J C and Henderson J 2000 In vitro selection and characterization of a drought tolerant clone of Tagetes minuta Plant Sci. 159 213-222

37. Kunakh V A 2011 Plasticity of the somatic cell genome and plant adaptability Molekuljarnaja i prikladnaja genetika (Molecular and applied genetics) 127

38. Mashkina O S, Butorina A K and Tabatskaya T M 2011 Karelian birch (Betula pendula Roth var. carelica Merkl.) as a model for studying genetic and epigenetic variation related to the formation of patterned wood Russ. J. Genetics 47 951-957 